\begin{tabular}{c|c|c}
\hline ISSN 2525-4812 (versão online) & Recebido em: 3/2/2019 & Revista Terceira \\
ISSN 2238-7641 (versão impressa) \\
$\begin{array}{c}\text { http://www.revistaterceiramargem.com/ } \\
\text { index.php/terceiramargem/index }\end{array}$ & $\begin{array}{c}\text { Aprovado em: 20/1/2020 } \\
\text { Período de publicação: jan., 2021 }\end{array}$ & $\begin{array}{c}\text { Margem Amazônia } \\
\text { (v. 6 • n. especial 16 • Jan. 2021) }\end{array}$ \\
\hline
\end{tabular}

Como citar o artigo:

HOMMA, A. K. O. Amazônia: venda de serviços ambientais ou de atividades produtivas? Revista Terceira Margem Amazônia. v. 6, n. especial 16, p. 23-34, 2021. DOI: http://dx.doi.org/10.36882/2525-4812.2021v6i16.ed.esp.p23-34

\title{
AMAZÔNIA: VENDA DE SERVIÇOS AMBIENTAIS OU DE ATIVIDADES PRODUTIVAS?
}

Alfredo Kingo Oyama Homma ${ }^{l}$

\begin{abstract}
Resumo: Reacendeu, nos últimos anos, a discussão sobre os rumos do desenvolvimento agrícola na Amazônia tendo como eixo a bioeconomia com base na "floresta em pé" a partir da coleta extrativa, venda de créditos de carbono e de serviços ambientais. Pretende-se com este texto chamar a atenção para aumentar a produtividade das atuais atividades agrícolas, reduzir a heterogeneidade tecnológica, apressar a transição florestal, proceder à domesticação de produtos extrativos que apresentam conflitos entre a oferta e a demanda e destravar a legislação sobre acesso à biodiversidade como imprescindíveis para reduzir a pobreza regional. A bioeconomia como apresentada repousa em proposições abstratas e potenciais que conflitam com a realidade presente.
\end{abstract}

Palavras-chave: Amazônia, desenvolvimento agrícola, serviços ambientais, bioeconomia.

\section{AMAZONIA: SALE OF ENVIRONMENTAL SERVICES OR PRODUCTIVE ACTIVITIES?}

\begin{abstract}
In recent years, the discussion on the direction of agricultural development in the Amazon has rekindled with the bioeconomy based on the "standing forest" based on extractive collection, sale of carbon credits and environmental services. The aim of this text is to draw attention to increase the productivity of current agricultural activities, reduce technological heterogeneity, accelerate the forest transition, proceed with the domestication of extractive products that present conflicts between supply and demand and unlock the legislation on access to biodiversity as essential to reducing regional poverty. The bioeconomy as presented rests on abstract and potential propositions in which it conflicts with the present reality.
\end{abstract}

Key words: Amazon, agricultural development, environment service, bioeconomy.

\footnotetext{
${ }^{1}$ Engenheiro-agrônomo, D. Sc. em Economia Aplicada, pesquisador da Embrapa Amazônia Oriental, Belém, PA. E-mail: alfredo.homma@embrapa.br

(D) https://orcid.org/0000-0003-0330-9858
} 


\section{Introdução}

Esta exposição foi apresentada na Mesa 1, intitulada "Serviços Ambientais: Desafios e Perspectivas para o Desenvolvimento e Sustentabilidade", no Workshop Serviços Ambientais: Perpectivas e Desafios para o Desenvolvimento Sustentável e Bem-Estar das Comunidades de Agricultores Familiares no Amazonas, realizado no período de 21 a 23 de novembro de 2018, em Manaus. Fizeram parte da mesa: Ademar Ribeiro Romeiro (Unicamp), Philip M. Fearnside (Inpa), Dione Torquato (CNS) e Eduardo Taveira (FAS), coordenado por Lindomar Silva e Denise Gutierrez.

Não resta dúvida de que a Amazônia presta relevantes serviços ambientais para o País e para o mundo como regulador climático e banco de germoplasma de interesse atual e para o futuro. A redução da cobertura florestal da Amazônia tem efeitos nas chuvas que beneficiam a agricultura no Sul e Sudeste e apresentam modificações climáticas de amplitude mundial. A redução da biodiversidade, grande parte dela ainda desconhecida da ciência, representa perdas nas possibilidades de descobertas de novos alimentos, medicamentos, corantes, perfumes, inseticidas, entre outros (HOMMA et al., 2020). A grande questão reside em quem vai pagar por esses serviços prestados para o País e para o mundo? ${ }^{2}$

Se o objetivo das nações desenvolvidas com relação à Amazônia seria o de reduzir desmatamentos e queimadas, as opções não estão na manutenção da floresta em pé para viver do extrativismo ou de crédito de carbono mediante desmatamento evitado, como querem as propostas de REDD+ (CARVALHO, 2018). Seria colocar os pequenos produtores, indígenas, quilombolas e ribeirinhos completamente dependentes de ONGs e movimentos sociais em vez de se dedicarem a atividades produtivas mais sustentáveis. Ou para justificar a manutenção das atividades não sustentáveis nos países desenvolvidos mediante a compra de serviços ambientais dos países subdesenvolvidos ou em desenvolvimento situados nas faixas tropicais.

A despeito da menção apenas dos serviços ambientais, existem outros tipos de benefícios palpáveis na região que não são comentados (WUNDER et al., 2008). Destaca-se a contribuição que a biodiversidade amazônica deu para o mundo, como foi a domesticação da cinchona, do cacaueiro, da seringueira, para mencionar as mais importantes. A domesticação da seringueira representou a maior conquista agronômica, desenvolvida no final do século XIX pelos ingleses. Provocou a mudança da extração de borracha de seringueiras disponíveis na natureza para plantations no Sudeste Asiático, mudando o eixo da produção, redução de custos, ampliação da oferta e a insustentabilidade do extrativismo.

A agricultura apresenta especificidade em relação ao setor industrial ou de serviços, por exemplo, de estarem crescendo ou produzindo, independentemente da presença dos operários, durante a noite ou fora do expediente. Apresenta limitações biológicas, de economia de escala, de catástrofes climáticas, entre os principais. A despeito das críticas ideológicas, o papel das plantations (dendezeiro, coqueiro, laranjeira, reflorestamento, guaranazeiro, açaizeiro, cana-de-açúcar) na geração de emprego, produtividade, conservação e preservação do meio ambiente, entre outros, precisaria ser estimulado na região.

\footnotetext{
2 A recente aprovação no Senado Federal (16/12/2020) e na Câmara dos Deputados (21/12/2020) do Projeto de Lei 5.028/2019, que cria a Política Nacional de Pagamento por Serviços Ambientais (PNPSA), foi transformada na Lei 14.119 (13/1/2021), pode dar nova configuração a essa proposta.
} 
As oportunidades econômicas para os pequenos produtores da região amazônica vão depender do desenvolvimento de atividades produtivas que atendam a segurança alimentar, produzam matérias-primas, intensivas em mão de obra, recuperem o passivo ambiental e gerem excedente para exportação de forma mais sustentável.

\section{Para que plantar?}

O interesse pelo plantio do cacaueiro (1746), efetuado antes da seringueira (1876), que foi levada para a Bahia e posteriormente para os continentes africano e asiático, transformou o fruto em um alimento global (MENDES, 2018). Para as plantas e animais pré-colombianos domesticados nos últimos dez mil anos, os detalhes históricos foram perdidos no tempo, como é emblemático para mandioca, tomate, batata inglesa, milho, amendoim, etc. Com relação a plantas e animais na Amazônia que estão sendo domesticados a partir do século XX, como guaranazeiro, pupunheira, cupuaçuzeiro, açaizeiro, pirarucu, etc., são efetuados por produtores, técnicos e pesquisadores, instituições, entre outros, com nomes e endereços, com relatos interessantes dessa aventura científica e tecnológica, superando os obstáculos. Para os jovens pesquisadores, a domesticação da biodiversidade amazônica representa uma oportunidade ímpar de pesquisa com lugar assegurado na história e benefício às populações regional, nacional e até mundial (HOMMA, 2017).

O capital extrativo tende a desestimular o esforço de plantio ou criação nas áreas de ocorrência, como aconteceu com a cinchona, a seringueira e o cacaueiro. "Se existe no mato, para que plantar?" constituiu uma opinião corrente, defendida não somente pelas populações locais, mas também por autoridades e, atualmente, por personalidades científicas e movimentos ambientais. Esse culto ao atraso tende, no médio e longo prazo, a prejudicar os produtores na busca de novas alternativas econômicas e os consumidores na disponibilidade de produtos de melhor qualidade e a custo mais reduzido (HOMMA, 2012, 2013).

As dificuldades ou o desinteresse na domesticação nas áreas de ocorrência, a existência de um mercado potencial, a incapacidade da oferta extrativa e o descaso da comunidade científica local conduzem à biopirataria. Em se tratando da biopirataria de produtos ativos na economia, ela leva a prejuízos socioeconômicos imediatos e potenciais para as plantas ou animais ainda sem utilização econômica. O atual discurso abstrato da bioeconomia, sem nominar esses recursos da flora ou fauna, revela algo fantasioso e potencial (HOMMA et al., 2020).

Os benefícios da biopirataria reversa, com entrada de plantas ou animais exóticos ou processos inovadores, ocorreram na Amazônia para juta, pimenta-do-reino, dendezeiro, bubalinos, eucalipto, etc. Os produtos agrícolas mais importantes do agronegócio brasileiro dependem da biodiversidade exótica (soja, frango, bovinos, suínos, café, laranja, eucalipto, etc.). Essas plantas e animais foram transferidos pelos imigrantes, pelos governos, empresas, pessoas isoladas, entre outros. Essa conduta, que era ética e moralmente permitida no passado, passou a ser regida pela Convenção sobre Diversidade Biológica (CDB), estabelecida durante a RIO 92, realizada no Rio de Janeiro em junho de 1992. 


\section{A pobreza regional}

Há uma grande pobreza regional. Considerando os dados do PNAD de 2018, 42,4\% da população da região Norte vivem na pobreza, dos quais 10,1\% vivem na extrema pobreza ("todas as pessoas que vivem em domicílios cuja renda domiciliar mensal per capita é inferior a 1/2 salário mínimo)". A taxa de pobreza do Brasil é de 26,0\% e de extrema pobreza, 6,5\% (IBGE, 2019).

A terrível pandemia da Covid-19, doença causada pelo coronavírus SARS-CoV-2, identificado pela primeira vez em seres humanos em dezembro de 2019 na cidade de Wuhan, China, e, em 26 de fevereiro de 2020, em São Paulo, mostrou a necessidade de melhorar no País a aplicação de recursos para os serviços de saúde pública, segurança alimentar, educação, transporte urbano, políticas sociais, em benefício dos desfavorecidos.

Tentar justificar a venda de serviços ambientais para melhorar as condições de vida dos pequenos produtores constitui alternativa inusitada e paradoxal. Há necessidade de intermediários ou de terceiros para viabilizar essas alternativas, que terminariam beneficiando o elo mais forte do sistema, representado pelo sistema bancário. Não seria mais apropriado depender de atividades produtivas concretas mais sustentáveis ao invés de benefícios abstratos?

\section{O desafio da transição florestal na Amazônia}

Uma transformação importante que precisa acontecer na Amazônia refere-se à transição florestal. Para que isso ocorra há necessidade de que a soma das áreas reflorestadas acrescida da recuperação das APPs e ARLs seja superior à área desmatada durante o ano. A supressão da cobertura florestal deverá ser compensada produzindo um desmatamento neutro, para atender a atividades agrícolas, obras de infraestrutura, crescimento populacional e demanda de alimentos (HOMMA, 2019b).

Como exemplos dessa transição mencionam-se os anos em que iniciou na Dinamarca (1810), França (1830), Suíça (1860), em Portugal (1870), na Escócia (1920), Costa Rica (1987), em vários estados americanos e verificam-se esforços de grande porte na China, que passou de 9\% de cobertura florestal em 1950 para 22\% em 2010 (KAUPPI et al., 2006; VERÍSSIMO; NUSSBAUM, 2011) (Tabela 1).

Na Amazônia a transição florestal vai ocorrer com percentual de cobertura florestal bastante elevado, ao contrário de países como Dinamarca, que iniciou com 4\%; Portugal com 7\%; França com 14\%; Costa Rica com 21\%, entre outros (KAUPPI et al., 2006). Países como Japão (62\%) e Estados Unidos (34\%) têm mantido o percentual de cobertura florestal praticamente intacto comparando-se os anos de 1900 e 2015 (VERÍSSIMO; NUSSBAUM, 2011; FAOSTAT, 2020) (Tabela 1). A antecipação da transição florestal repousa, essencialmente, no aumento da produtividade agrícola, evitando a expansão horizontal da agricultura, e da melhoria do capital social. A grande questão é: quando é que vai ocorrer, daqui a 5, 10 ou 20 anos? Vai depender de investimentos em C\&T, de melhoria do serviço de extensão rural, da qualidade dos agricultores, das atividades a serem desenvolvidas, do crescimento populacional e da demanda de alimentos, entre as principais, tanto locais como externas à Amazônia (ALVES; HOMMA, 2019). 
Tabela 1. Percentual de área florestal de alguns países selecionados quando ocorreu a transição florestal e a disponibilidade de floresta e a sua natureza (nativa, plantada ou regenerada) em 2015.

\begin{tabular}{|c|c|c|c|c|c|c|}
\hline \multirow{2}{*}{ Países } & \multicolumn{2}{|c|}{ Transição florestal } & \multirow{2}{*}{$\begin{array}{c}\text { Cobertura florestal } \\
\text { do país } 2015 \\
\%\end{array}$} & \multirow{2}{*}{$\begin{array}{c}\text { Floresta } \\
\text { natural } \\
\%\end{array}$} & \multirow{2}{*}{$\begin{array}{c}\text { Floresta } \\
\text { plantada } \\
\%\end{array}$} & \multirow{2}{*}{$\begin{array}{c}\text { Regeneração } \\
\text { natural } \\
\%\end{array}$} \\
\hline & Ano & $\%$ & & & & \\
\hline Dinamarca & 1810 & 4 & 14,26 & 5,55 & 75,79 & 18,65 \\
\hline Portugal & 1870 & 7 & 34,50 & 0,76 & 28,00 & 71,24 \\
\hline Holanda & 1950 & 8 & 9,05 & 0 & 100 & 0 \\
\hline China & 1950 & 9 & 21,70 & 5,58 & 37,91 & 56,50 \\
\hline Reino Unido & 1950 & 9 & 12,90 & 0 & 86,39 & 13,61 \\
\hline França & 1830 & 14 & 30,94 & 0 & 11,58 & 88,42 \\
\hline Costa Rica & 1987 & 21 & 53,93 & 65,83 & 0,64 & 33,53 \\
\hline Índia & 1950 & 22 & 18,47 & 22,21 & 17,02 & 60,76 \\
\hline Polônia & 1950 & 24 & 30,17 & 0,62 & 94,93 & 4,44 \\
\hline Alemanha & 1950 & 28 & 31,94 & 0 & 46,37 & 53,63 \\
\hline Estados Unidos & 1900 & 34 & 31,54 & 24,28 & 8,50 & 67,21 \\
\hline Suécia & 1950 & 56 & 62,74 & 8,61 & 48,93 & 42,46 \\
\hline Japão & 1950 & 62 & 66,03 & 19,65 & 41,15 & 39,20 \\
\hline
\end{tabular}

Fonte: Kauppi et al. (2006), Veríssimo e Nassbaum (2011) e FAOSTAT (2020).

Na Amazônia a reconversão da cobertura florestal deverá atingir um limite a partir do qual não será possível aumentar. Foram desmatados, até 2018, aproximadamente 19\% da cobertura florestal e ainda deverá crescer nos próximos anos (500 mil a 1.100 mil hectares/ano), para então atingir o desmatamento neutro e começar a aumentar a cobertura florestal. A maior possibilidade de repor a cobertura florestal repousa na redução das áreas de pastagem, tanto daquelas em bom estado (37,7 milhões de hectares) como dos pastos sujos + pastos em regeneração (10,2 milhões de hectares), das áreas com culturas anuais + mosaico de ocupação (1,6 milhão de hectares), supondo algo em torno de 15 milhões de hectares (Tabela 2). Dessa forma a redução mínima possível deve ficar em torno de 5\%, resultando numa área disponível em torno de $15 \%$ da Amazônia Legal para agricultura, cidades, mineração, obras de infraestrutura na Amazônia.

Tabela 2. Uso da terra na Amazônia identificado pelo Projeto Terraclass (ha).

\begin{tabular}{|c|c|c|c|c|}
\hline Classe & 2008 & 2010 & 2012 & 2014 \\
\hline Agricultura anual & 3.492 .724 & 3.997 .785 & 4.234 .640 & 4.505 .000 \\
\hline Mosaico de ocupação & 2.441 .700 & 1.796 .300 & 959.000 & 1.625 .600 \\
\hline Pasto limpo & 33.571 .495 & 33.985 .187 & 34.541 .985 & 37.747 .000 \\
\hline Pasto sujo & 6.282 .376 & 5.607 .664 & 5.047 .211 & 6.026 .200 \\
\hline Regeneração com pasto & 4.802 .737 & 6.316 .546 & 4.646 .812 & 4.202 .800 \\
\hline Vegetação secundária & 15.081 .531 & 16.522 .931 & 17.218 .978 & 17.338 .700 \\
\hline Total desmatado & 70.775 .236 & 73.967 .253 & 75.134.047 & 76.246 .400 \\
\hline
\end{tabular}

Fonte: PROJETO... (2018).

Para isso será necessário que programas de pesquisa agrícola, em um cenário sem desmatamentos e queimadas, sejam estabelecidos. A criação de gado extensiva não terá mais espaço nesse novo cenário, exigindo uma criação intensiva, tal qual a adotada pelos europeus, como se fosse 
granja avícola. A piscicultura, pela maior produtividade por área, deverá substituir a proteína bovina e com menor impacto ambiental. A reciclagem da água e do lixo urbano apresenta também desafios para a pesquisa agrícola e ambiental.

Há fenômenos em curso na Amazônia, como a mudança da "pecuarização" para a "agriculturização", promovendo a substituição das áreas de pastagem degradada por cultivo de grãos, de dendezeiro, de fruteiras, além de reflorestamento, pecuária mais intensiva, etc. Essa transformação está evidente nas áreas mais dinâmicas dos estados de Mato Grosso, Rondônia, do Pará, Maranhão e Tocantins (HOMMA, 2019a).

Não há informações sobre as características dos agentes responsáveis pelo desmatamento, mas pode-se especular que uma fatia da área desmatada na Amazônia, com área média da propriedade elevada, foi realizada pelos migrantes paulistas, paranaenses, capixabas, mineiros, gaúchos, catarinenses, etc., estimulados pelos incentivos fiscais da Superintendência do Desenvolvimento da Amazônia (Sudam), da oferta de terras, da abertura das estradas e do mercado de carnes e de madeira. Adicionam-se os pequenos produtores nordestinos e do Sul e Sudeste, com área média de propriedade menor, mas com efeito quantitativo maior, pela redução da cobertura florestal. Os imigrantes japoneses e seus descendentes também induziram de forma direta e indireta o desmatamento nas áreas de várzea, com a introdução da juta e da pimenta-do-reino nas áreas de terra firme, entre outros. A agricultura de subsistência e a demanda por produtos agrícolas têm sido a causa da expansão das atividades produtivas na região. Por exemplo, o enfoque de culpar os criadores de gado (oferta) pelo desmatamento desconhece os consumidores de carne (demanda) como força indutora do desmatamento (HOMMA, 2019b).

Os agricultores têm uma oportunidade ímpar de contribuir para reduzir o passivo ambiental de suas propriedades agrícolas. Em vez de ficar preocupados com o aquecimento global como objetivo abstrato, devem buscar medidas concretas que podem ser executadas por eles: aumentar a produtividade das atividades produtivas, promover a recuperação de cursos de água, evitar a queima de resíduos, entre outros. Criando as condições favoráveis, a própria natureza apresenta uma rápida capacidade de recuperação.

A transição florestal só será possível se contar com a cooperação do setor produtivo. No dia 30/5/2008, o governo federal lançou, em Belém, um programa de plantio de um bilhão de árvores na Amazônia (VIEIRA et al., 2008). Essa proposta tinha uma meta visível, mas não teve o apoio dos empresários, dos produtores, das comunidades nem da sociedade, não constituindo um problema premente. A cifra que a primeira medida espantava pelo número para a Amazônia representava apenas o passivo das guseiras, que já deveriam ter reflorestado um milhão de hectares com eucaliptos para substituir o carvão vegetal utilizado de florestas nativas. $O$ custo das decisões incorretas, a corrupção e o egoísmo com a questão coletiva vêm conduzindo a uma dupla tragédia na Amazônia: a dos commons e dos anticommons, sobretudo àquelas relacionadas a questões ambientais, com a interferência de diversos agentes (Ibama, Ministério Público Estadual, Ministério Público Federal, ONGs, etc.) (HARDIN, 1968; HELLER, 1998).

Para reduzir desmatamentos e queimadas na Amazônia há necessidade de reduzir custos de recuperação de áreas degradadas, garantir segurança jurídica e patrimonial para os produtores, ampliar os esforços de pesquisa agrícola focados em resolver os problemas dos produtores, me- 
lhorar a infraestrutura já instalada, coibir os ilícitos, reduzir a burocracia para o setor agrícola, entre os principais.

\section{Desafios da legislação}

A legislação de acesso à biodiversidade emanada da Lei $n^{0} 13.123 / 2015$ e Decreto 8.772/2016, que foi estabelecida para repartir benefícios para as populações tradicionais, ribeirinhas, indígenas e quilombolas, está completamente equivocada. Pressupõe-se que toda pesquisa envolvendo biodiversidade geraria lucro para ser repartido. Trata-se de uma legislação incorreta que termina prejudicando a pesquisa sobre a biodiversidade na descoberta de fármacos, cosméticos, corantes, inseticidas, novos alimentos, entre outros, gerando renda e emprego. A busca por genes em vez de plantas (tomate, batatinha), desenvolvimento de híbridos (dendezeiro africano $\mathrm{x}$ dendezeiro nativo da Amazônia), plantas sem utilidade no presente, que exigem escala na produção e pesados investimentos, que necessitam de complexos processos de beneficiamento, tempo para a sua viabilização, entre outros, justificam a repartição de benefícios?

O aperfeiçoamento da legislação sobre a conservação e a preservação da floresta, como a Lei $n^{\circ} 12.651$ de 25/5/2012 (Código Florestal), é necessário para apressar a transição florestal na região. É importante definir metas concretas para cumprir o passivo ambiental representado pelas APPs e ARLs. Margens de cursos de água deveriam receber maior atenção, como também áreas impróprias para agricultura que foram desmatadas no passado para garantir a posse; desmatamento de vegetação secundária em vez de floresta densa; mudanças de atividades degradadoras e improdutivas, entre outros. No estado do Pará, em 2018, existiam 1.066 PAs, com 225 mil assentados ocupando 16,5 milhões hectares, que representa 13\% do estado do Pará ou quase dois estados de Santa Catarina ou quase do tamanho do Uruguai, distribuídas em três superintendências do Incra. Com exceção para determinados cultivos, como de cacaueiro, pimenta-do-reino, hortaliças, fruteiras, a maioria desses assentamentos apresenta baixa produtividade, não recebe assistência técnica, depende de programas de transferência governamental, não apresenta escala de produção, entre outros. Essa situação se repete em outras unidades federativas da Amazônia. Seria muito mais apropriado se essas terras fossem arrendadas para outros usos.

\section{Ampliar a oferta de tecnologia}

A reduzida capacidade de geração de tecnologia local constitui um dos maiores obstáculos para aumentar o grau de sustentabilidade da agricultura regional. Ocorreu um avanço na expansão da fronteira científica sobre a região em termos de conhecimento sobre flora, fauna, clima, meio ambiente, entre outros. Ressalta-se, contudo, que o conhecimento sobre culturas anuais e perenes, extrativismo vegetal e animal, reflorestamento, piscicultura, etc. são ainda bastante restritas, com produtores baseando-se no processo de tentativa e acerto. Predominam ainda o conhecimento indígena, os trazidos pelos imigrantes nacionais e externos e a tecnologia gerada nas áreas fora da Amazônia ou do exterior. A existência de um avançado aparato de pesquisa agrícola no Sul e Sudeste facilitou o processo de drenagem de conhecimento da seringueira (spillovers), troca de conhecimento entre as regiões beneficiadas (spillins), e do retorno de problemas para as fontes geradoras (spillbacks), já com reduzida capacidade de pesquisa (ARAJI, 1983; BONELLI; 
PESSOA, 1988; ARAJI et al., 1995; SCHIMMELPFENNIG; THIRTLE, 1999; JOHNSON; EVENSON, 2000; MAREDIA; BYERLEE, 2000).

A crítica quanto à inviabilidade da agricultura na Amazônia pode ser contestada pela existência de alternativas mais sustentáveis na região amazônica: o desenvolvimento da piscicultura, reflorestamento, pecuária intensiva, cacaueiro, açaizeiro, novas plantas da biodiversidade, segurança alimentar, aumento da produtividade das culturas tradicionais, entre as principais. Mesmo para as atividades consideradas depredadoras é possível um desenvolvimento mais sustentável. Para a concretização dessas atividades há necessidade de ações visando aproveitar o lixo urbano, armazenamento e reúso de água, viabilizar agroindústrias, melhorar as estradas, gerar continuamente novas tecnologias, melhorar a assistência técnica, entre outras.

\section{Reduzindo a heterogeneidade tecnológica da agricultura amazônica}

No universo de produtores, sejam eles pequenos, médios ou grandes, verifica-se que a produtividade agrícola (planta ou criação) não é uniforme. Isolando as causas sociais (educação formal, saúde, etc.), econômicas (infraestrutura, proximidade de mercado, assistência técnica, etc.), ambientais (solos mais férteis, microclima favorável, etc.), existem as variáveis agronômicas, zootécnicas ou veterinárias, que poderiam ser aperfeiçoadas, adotando-se as práticas mais recomendáveis. Neste sentido, a redução da heterogeneidade tecnológica da produtividade das lavouras e a utilização das tecnologias daqueles produtores inovadores (produção de novos produtos) poderiam promover um impacto local ou regional em locais mais atrasados (PENNA; MUELLER, 1977). Não se descarta a importância do desenvolvimento de tecnologias para possibilitar a ocupação de áreas consideradas pouco viáveis e da intensificação da produção agrícola, pela remoção de obstáculos ao uso mais eficiente de terras das propriedades já formadas.

Tomando-se o exemplo do cacaueiro, em palestra proferida pelo pesquisador Manfred Willy Muller, em 2014, verifica-se que a heterogeneidade da produtividade do cacaueiro poderia ser nivelada mediante a passagem de uma fração dos produtores de baixa produtividade para média produtividade, e desta para alta produtividade (Tabela 3). Ressalta-se que essa medida serve como programa emergencial de curto prazo para as regiões atrasadas, decorrente da escassez da oferta tecnológica, com resultados em longo tempo. Direcionar uma instituição de pesquisa e seus pesquisadores somente para essa linha correria o risco do seu esvaziamento no contexto de médio e longo prazos.

As tecnologias de natureza mecânica, como máquinas e implementos agrícolas, indústria química (herbicidas, fungicidas, etc.), ou biológica, como novas cultivares, são facilmente adotadas quando comprovadas a sua eficiência e rentabilidade. No caso de tecnologias agrícolas (fitotécnicas, zootécnicas, etc.), o procedimento é mais lento e complexo, mas determinadas práticas agrícolas são passíveis de serem adotadas. Dias de Campo ou Unidades Demonstrativas poderiam ser efetuados nas propriedades que apresentam melhor desempenho agrícola. $\mathrm{O}$ fato de exemplos serem dos próprios produtores, as possibilidades seriam maiores quanto a sua adoção. A identificação desses sistemas mais eficientes seria trabalho dos pesquisadores de ciências sociais associados com pesquisadores das áreas de agronomia, de criação, florestais e veterinárias. 
Tabela 3. Caracterização das áreas de cacaueiro plantadas por faixas de produtividade (2012).

\begin{tabular}{|c|c|c|c|c|c|c|c|}
\hline \multirow{2}{*}{$\begin{array}{c}\text { Faixas de } \\
\text { produtividade } \\
(\mathrm{kg} / \mathrm{ha})\end{array}$} & \multicolumn{7}{|c|}{ Área plantada (ha) } \\
\hline & Bahia & Pará & Rondônia & $\begin{array}{c}\text { Espírito } \\
\text { Santo }\end{array}$ & Amazonas & $\begin{array}{c}\text { Mato } \\
\text { Grosso }\end{array}$ & Total \\
\hline Inferior a $420 \mathrm{~kg} / \mathrm{ha}$ & 403.922 & 1.463 & 336 & 21.442 & 5.454 & 85 & 432.702 \\
\hline Entre 420 e $749 \mathrm{~kg} / \mathrm{ha}$ & 87.383 & 31.025 & 29.819 & 442 & 5.258 & 263 & 154.190 \\
\hline Superior a $750 \mathrm{~kg} / \mathrm{ha}$ & 7.400 & 55.779 & 0 & 202 & 0 & 523 & 63.904 \\
\hline Em desenvolvimento & 29.320 & 34.307 & 10.121 & 1.222 & 2.372 & 0 & 77.742 \\
\hline Total & 540.383 & 126.574 & 40.757 & 23.308 & 13.084 & 871 & 740.977 \\
\hline
\end{tabular}

Fonte: Muller (2014).

\section{Conclusões}

Seminários dessa natureza são importantes, por isso a necessidade de maior divulgação para o público leigo. A desinformação com relação à agricultura amazônica é muito grande, mesmo na área acadêmica e nos meios de comunicação pública, associada à questão ideológica decorrente da simples ignorância, da desconfiança da sociedade com relação a qualquer tipo de informação ou da vulgarização com que assuntos importantes são apresentados.

A sequência de desastres ambientais no estado do Pará, como o ocorrido com a Hydro Alunorte em 17/2/2018, o rompimento das barragens em Paragominas em 12/4/2018, o afundamento do navio Haidar de bandeira libanesa no porto de Vila do Conde com carregamento de cinco mil bois vivos em 6/10/2015, reforça a necessidade de direcionar o foco da questão ambiental. Somam-se a essas tragédias a da mineradora Samarco, ocorrida em 5/11/2015, e da Vale, em Brumadinho, em 25/1/2019, ambas em Minas Gerais, que mostram o descaso, a irresponsabilidade das empresas e autoridades e da área acadêmica, desfocada para outros assuntos (comunicação pessoal) ${ }^{3}$. Esses desastres ambientais não devem ser utilizados para coibir a agricultura na Amazônia, e sim para mostrar as consequências do descumprimento das leis, a falta de fiscalização e a busca dos atalhos fáceis.

Na Amazônia, a questão ambiental se resume à supressão da cobertura florestal associada aos interesses de algumas entidades nacionais e internacionais na captação de recursos e do controle político do espaço representado por comunidades indígenas, quilombolas e pequenos produtores com níveis de pobreza absoluta. A geração de renda e emprego vai depender do desenvolvimento de tecnologias que criem alternativas econômicas e da existência de mercados que consigam coevolucionar.

Os extrativismos vegetal e animal têm sido a causa do atraso e da passividade secular, sem a preocupação com sua baixa produtividade e esgotamento futuro. Produtos da biodiversidade baseados no extrativismo que tiveram grande peso na região foram transferidos para outras partes do País e do mundo, constituindo-se em fontes de riqueza nesses novos locais, ou do limite da capacidade de oferta.

\footnotetext{
3 Notícia fornecida por J. B. Assis em Brumadinho, em 29 de janeiro de 2019.
} 
Torna-se urgente desenvolver uma agenda de pesquisa que consiga coevolucionar a segurança alimentar, promover a agroindustrialização e gerar excedente exportável com a transição florestal no espaço de tempo mais curto possível. As propostas externas sobre a região têm gerado conflitos com as aspirações passivas da população local. Grandes projetos minerais, hidrelétricos e de logística estão em curso ou planejados. Há necessidade de o setor agrícola se inserir nesse contexto e contornar desafios ambientais e legais.

Atividades intensivas em mão de obra, da dificuldade em mecanizar alguma parte do processo produtivo ou de apropriar economias de escala, apresentam maior competitividade para os pequenos produtores. Enquadram-se nessa categoria hortaliças, fruteiras (cacaueiro, cupuaçuzeiro, açaizeiro, etc.), seringueira, pimenta-do-reino, baunilha, entre outros.

A "judicialização" da questão ambiental baseada apenas na "indústria das multas" ou das proibições leva à subjetividade de os impactos serem baixos, médios ou altos. Seria mais apropriado obrigar a mitigar, reparar e conservar os danos provocados, mediante um termo de ajustamento de conduta. A multa deveria ser o último ato, e não o primeiro. Esses enfoques seriam fáceis de serem conduzidos quando envolvem a vertente produtiva, mas bastante complexos para APPs e ARLs, cidades, infraestrutura, entre outros.

Os agricultores da Amazônia não são avessos a inovações, desde que tenham mercado e sejam lucrativas. Em vez da criação de mercados difusos ou artificiais, como a venda de créditos de carbono ou serviços ambientais, a solução precisa ser encontrada com a criação de alternativas tecnológicas e econômicas. A população precisa de alimentos e matérias-primas com menor dano ambiental.

A Amazônia precisa aumentar sua produtividade agrícola para reduzir a pressão sobre os recursos naturais, promover a domesticação de plantas potenciais e substituir importações (interna e externa) de produtos tropicais (borracha, dendê, cacau, arroz, leite, aves, ovos, hortaliças, etc.) e incentivos à recuperação de áreas que não deveriam ter sido desmatadas.

Os problemas ambientais na Amazônia não são independentes, mas conectados a outras partes do País e do mundo, e sua solução vai depender da utilização parcial da fronteira interna alterada e de um forte aparato de pesquisa científica e de extensão rural. Maior fiscalização e supressão de atos ilícitos, como desmatamentos, queimada e retirada de madeira ilegal, garimpos, narcotráficos, contrabando de animais e outros, precisam ser eliminados na região. Há necessidade de se construir o futuro da Amazônia em um cenário com desmatamento neutro, independentemente de pressões externas.

\section{Referências}

ALVES, R. N. B.; HOMMA, A. K. O. O fogo na agricultura da Amazônia. In: ALVES, R. N. B.; MODESTO JÚNIOR, M. de S. (Ed.). Roça sem fogo: da tradição das queimadas para a agricultura sustentável na Amazônia. Brasília, DF: Embrapa, 2019. p. 35-40.

ARAJI, A. A. The economic impact of investment in integrated pest management. In: WORKSHOP SOBRE METODOLOGIAS DE AVALIAÇÃO SOCIOECONÔMICA DA PESQUISA AGROPECUÁRIA, 1983, Brasília, DF. Selected readings. Brasília, DF: EMBRAPA-DEP, 1983. v. 4. p. 121-139. 
ARAJI, A. A.; WHITE, F. C.; GUENTHNER, J. F. Spillovers and the returns to agricultural research for potatoes. Journal of Agricultural and Resource Economics, v. 20, n. 2, p. 263-276, Dec. 1995.

BONELLI, R.; PESSÔA, E. de P. O papel do estado na pesquisa agrícola no Brasil. Brasília, DF: IPEA, 1998. 45 p. (Texto para Discussão, 576).

CARVALHO, E. F. de. La protección de los bosques naturales a la luz del derecho ambiental internacional y la constitución brasileña: ¿Serán capaces de salvar la Floresta Amazónica?. Belém, PA: NAEA, 2018. $418 \mathrm{p}$.

FAOSTAT. Land use. Disponível em: http://www.fao.org/faostat/en/\#data/RL>. Acesso em: 29 out. 2020.

HARDIN, G. The tragedy of the commons. Science, v. 162, p. 1243-1248, Dec. 1968.

HELLER, M. A. The tragedy of the anticommons: property in the transition from Marx to markets. Harvard Law Review, v. 3, n. 111, p. 621-688, jan. 1998.

HOMMA, A. K. O. A questão da produção do conhecimento regional e a biodiversidade. In: LINS NETO, J. T.; LOPES, M. L. B. 1912-2012 cem anos da crise da borracha: do retrospecto ao prospecto: a Amazônia em doze ensaios: coletânea do VI ENAM. Belém, PA: CORECON-PA, 2013. p. 121-145.

HOMMA, A. K. O. A terceira natureza da Amazônia. Revista Paranaense de Desenvolvimento, v. 38, n. 132, p. 27-42, jan./jun. 2017.

HOMMA, A. K. O. Plant extractivism or plantations: what is the best option for the Amazon? Estudos Avançados, v. 74, n. 26, p. 167-186, 2012.

HOMMA, A. K. O. "Agriculturização" na Amazônia: conflitos e oportunidades. In: SILVA, L. de J. de S.; PINHEIRO, J. O. C.; MUNIZ, A. W. (Ed.). Pesquisa e agricultura familiar: intercâmbio de ações e conhecimentos para transferência tecnológica na Amazônia. Manaus: Embrapa Amazônia Ocidental, 2019a. p. 13-41

HOMMA, A. K. O. Amazônia: a civilização do fogo. In: ALVES, R. N. B.; MODESTO JÚNIOR, M. de S. (Ed.). Roça sem fogo: da tradição das queimadas para a agricultura sustentável na Amazônia. Brasília, DF: Embrapa, 2019b. p. 11-33.

HOMMA, A. K. O; MENEZES, A. J. E. A. de; SANTANA, C. A. M.; NAVARRO, Z. O desenvolvimento mais sustentável da região amazônica: entre (muitas) controvérsias e o caminho possível. Colóquio Revista do Desenvolvimento Regional, Faccat-Taquara/RS, v. 17, n. 4, p. 1-27, out./dez. 2020.

IBGE. Síntese de indicadores sociais: uma análise das condições de vida da população brasileira: 2019. Rio de Janeiro, 2019. 130 p. (Estudos e pesquisas. Informação demográfica e socioeconômica; n. 40). Disponível em: https://biblioteca.ibge.gov.br/visualizacao/livros/liv101678.pdf>. Acesso em: 29 out. 2020.

JOHNSON, D. K. N.; EVENSON, R. E. How far away is Africa? Technological spillovers to agriculture and productivity. American Journal of Agricultural Economics, n. 82, p. 743-749, 2000.

KAUPPI, P. E.; AUSUBEL, J. H.; FANG, J.; MATHER, A. S.; SEDJO, R. A.; WAGGONER, P. E. Returning forests analyzed with the forest identity. Proceedings of the National Academy of Sciences, v. 103 , n. 46 , p. $17574-17579,14$ nov. 2006.

MAREDIA, M. K.; BYERLEE, D. Efficiency of research investments in the presence of international spillovers: wheat research in developing countries. Agricultural Economics, v. 22, n. 1, p. 1-16, 2000. 
MENDES, F. A. T. Agronegócio do cacau no Estado do Pará: origem e desenvolvimento. Belém, PA: Clube dos Autores, 2018. $201 \mathrm{p}$.

MUller, M. W. Programa de Desenvolvimento Sustentável das Regiões Produtoras de Cacau (PRODECACAU). Produção com responsabilidade social. Brasília, DF: Câmara Setorial da Cadeia Produtiva do Cacau, 2014.

PENNA, J. A.; MUELLER, C. C. Fronteira agrícola, tecnologia e margem intensiva: algumas reflexões sobre o papel desses fatores para o crescimento agrícola brasileiro. Estudos Econômicos, v. 7, n. 1, p. 53 106, jan./abr. 1977.

PROJETO Terraclass 2014. Mapeamento do uso e da cobertura da terra na Amazônia Legal brasileira. 2018. Disponível em: http://www.inpe.br/cra/projetos_pesquisas/terraclass2014.php. Acesso em: 22 fev. 2019.

SCHIMMELPFENNIG, D.; THIRTLE, C. The internationalization of agricultural technology: patents, R\&D spillovers, and their effects on productivity in the European Union and United States. Contemporary Economic Policy, n. 17, p. 457-469, 1999.

VERÍSSIMO, A.; NUSSBAUM, R. Um resumo do status das florestas em países selecionados - nota técnica. São Paulo: Greenpeace, 2011. 54 p.

VIEIRA, I. C. G.; VEIGA, J. B. da; YARED, J. A. G.; SALOMÃO, R. de P.; OHASHI, S. T.; BRIENZA JUNIOR, S.; TENÓRIO, C.; SILVEIRA, E.; BIAZZATTI, M. Bases técnicas e referenciais para o programa de restauração florestal do Pará: um bilhão de árvores para a Amazônia. Belém, PA: Instituto de Desenvolvimento Econômico, Social e Ambiental do Pará, 2008. 103 p. (Pará Desenvolvimento, 2).

WUNDER, S.; BORNER, J.; RUGNIZ, M.; PEREIRA, L. Pagamentos por serviços ambientais: perspectivas para a Amazônia Legal. Brasília, DF: Ministério do Meio Ambiente, 2008. 136 p. (Série Estudos, 10). 